\title{
Los médicos judíos de Huesca, según los protocolos notariales del siglo XV
}

Eugenio Benedicto Gracia

Recopilación y ordenación de la documentación existente en el Archivo Histórico Provincial de Huesca referida a los médicos judíos de la ciudad desde fines del siglo XIV y durante casi todo el siglo XV. La información inédita recogida en los protocolos notariales (complementada con otra documentación ya publicada) no es extraordinaria, pero nos da una idea de algunas de las actividades desarrolladas por los 36 médicos judíos de Huesca. Los datos propiamente médicos son escasos, aunque permiten conocer otras facetas de sus actividades y vida cotidiana.

PALABRAS CLAVE: Huesca; siglo XV; médicos judíos; vida cotidiana; protocolos notariales.

The Jemish Physicians in Huesca, According to $15^{\text {th }}$ Century Notarial Records. - Collection and analysis of the documentary evidence taken from the notarial records at the Archivo Histórico Provincial de Huesca, concerning Jewish physicians in the city throughout the $15^{\text {th }}$ century. The unpublished evidence that has been collected from these sources does not provide us with an outstanding information, especially regarding medical aspects; however, it sheds some light on different aspects of the everyday life of 36 Jewish physicians documented in Huesca.

KeYwords: Huesca; $15^{\text {th }}$ Century; Jewish Physicians; Everyday Life; Notarial Records.

Después de haber recogido todo el material referido a los médicos judíos que contienen los protocolos del Archivo Histórico Provincial de Huesca, nos encontramos con un número verdaderamente importante de ellos que, además de ocupar puestos directivos en la aljama, participan en diversas actividades de la vida ordinaria de la ciudad. Lamentablemente, la documentación, salvo unos pocos casos de peritaje y contratos de curación, apenas proporciona datos referidos a la ciencia médica, extremo que hubiera sido muy interesante conocer ${ }^{1}$.

Las referencias acerca de la presencia de médicos judíos en Huesca comienzan con la misma conquista cristiana de la ciudad. Es el caso de Pedro Alfonso, bautizado en 1106; o del cirujano Samuel, que sirvió al rey de Aragón a fines del siglo xIII. Asímismo, hay constancia en 1307 de dos médicos judíos, Abrahime

${ }^{1}$ A este respecto, vid. las reflexiones de A. Blasco Martínez, «Médicos y pacientes de las tres religiones (Zaragoza siglo XIV y comienzos del Xv)», Aragón en la Edad Media 12 (1995), págs. 153-182: 157, donde presenta las peculiaridades de la información recogida en los protocolos zaragozanos del siglo XIV. 
Alphamel y David Abulbaca, o del médico judío de la infanta Blanca, priora del monasterio de Sijena, en 1323. El obispo Vidal Canellas menciona en su testamento de 1252 al «alfaquino» Abrayme Aborrabe, y el dominico Ademar dejó en 1300 al físico «Juceph» un dinero.

La consulta de los protocolos notariales permite aumentar sustancialmente la nómina de médicos judíos conocidos, cuya relación se presenta a continuación según la primera y última fechas en que aparecen citados en la documentación estudiada. De estos 36 documentados, un buen número coinciden en el tiempo. Así, entre 1351-1434 son 7; otros 7 entre 1434-45; 13 entre 1445-56; 11 entre 1456-64; 23 entre 1464-76; y 15 entre 1476-89.

\section{NómINA DE MÉDICOS JUdíos DE HuesCA}

\section{Familia Abenardut}

1. Jucé Avinardut (29-VII-1351 - 4-VII-1414).

2. Haym Avinardut (I-1398 - 8-III-1452).

3. Jucé Avinardut (21-VI-1405 - 10-V-1434).

4. Astruch Avinardut, alias Cohén (9-IX-1457 - 1-V-1478).

\section{Familia Cavatierra}

5. Astruch Cavatierra (13-XI-1407 - 16-III-1434).

6. Açach Cavatierra (5-II-1428 - 3-IX-1436).

7. y 8. Jehudá Cavatierra, padre e hijo (13-VI-1428 - 7- IV-1483).

9. Sentó Cavatierra (1440 - 1-V-1476).

\section{Familia Arrondí}

10. Mossé Arrondí (7-V-1455 - 25-XI-1479).

11. Açach Arrondí (28-VI-1442 - 21-VII-1490).

\section{Familia Cap}

12. Vidal Cap (2-XI-1445 - 11-VI-1473).

13. Acach Cap (18-XI-1464 - 7-I-1480).

14. Jucé Cap (17-IV-1475).

15. Salter Cap (21-XII-1479).

\section{Familia Bivach}

16. Abram Bivach (7-I-1456 1-V-1471).

17. Acach Bivach (6-VI-1480 - 11-XII-1489).

18. Gentó Bivach (20-XI-1455 - 19-XII-1459). 


\section{Familia Avendet}

19. Jucé Avendet (3-XI-1474 - 8-VI-1477).

20. Ezmel Avendet (28-III-1475 - 26-XI-1483).

\section{Familia Alazar}

21. Jucé Alazar (4-VII-1475 - 6-V-1476).

22. Mossé Alazar (25-VI-1481).

\section{Otros médicos}

23. Jucé Almacarén (22-I-1445).

24. Nicín Hanoqua (10-I-1448 - 6-VI-1486).

25. Abram Usiello (1453 - 1-V-1478).
26. Mossé Cucumbriel (14-XI-1454).

27. Mossé Cohén (3-III-1456).

28. Eliezer Alintienz (1467).

29. Abram Papur (24-VIII-1470).

30. Jucé Tadroz (10-XI-1474).

31. Salamón Natán (2-II-1475 - 14-V-1476).

32. Jucé d'Ixía (15-IV-1475).

33. Jucé Frad (15-IV-1475).

34. Salamón Ampinaz (23-I-1476).

35. Acach Xuén (4-II-1480 - 26-VIII-1490).

36. Dolz Alnieto (4-IX-1480 - 14-V-1482).

De acuerdo con Cardoner y Vendrell, la familia Abenardut, de la que formaban parte varios médicos reales, procedería originalmente de Tudela, donde existía un núcleo judío del que algunos miembros se desplazarían a Zaragoza, Huesca, Lérida y Valencia ${ }^{2}$. Basándonos en estos antecedentes, creemos que el maestre Alatzar que aparece en los registros de Cancillería de Alfonso el Benigno y Pedro el Ceremonioso, podría tener relación con «Jamila, fillya de maestre Alatzar Avinardut, quondam», que figura como beneficiaria del testamento de Alatzar Çadot de 3 de septiembre de 1415 sin que, por otra parte, nos sea posible establecer una relación genealógica precisa (Apéndice, doc. $\mathrm{n}^{\mathrm{o}} 3$ ).

La primera noticia que tenemos referente a Jucé Abenardut (1) es de 20 de febrero de 1351. En esa fecha, el monasterio de Sijena da a su hijo Mossé unas casas en el barrio Amalbel, que confrontan con las suyas propias ${ }^{3}$. Con anterioridad a esta fecha, sabemos que Jucé era médico de la reina Leonor y de los infantes desde 1349.

Hasta el 29 de junio de 1381 no volvemos a tener más datos de Jucé, apareciendo en esta fecha como testigo en un pago que Jehudá Abadías hace,

2 A. Cardoner Planas y F. Vendrell Gallostra. «Aportaciones al estudio de la familia Abenardut, médicos reales», Sef 7 (1947), págs. 303-348.

${ }^{3}$ Archivo Histórico Provincial de Huesca [en adelante, AHPH], Docs. Sijena, leg. 3, no 2. 
junto con Lop lo Nieto y Daví Abinbag, de 160 s. correspondientes a una deuda de 1.170 s. ${ }^{4}$. El 26 de enero de 1394 se registra una deuda de 500 s. debida por «maestre Jucé Avinardut, phísigo del senyor Rey» ${ }^{5}$. En enero de 1398 consta su examen para físico en Huesca ${ }^{6}$. En este mismo año, a 5 de junio, Jucé es mencionado en dos ocasiones como adelantado de la aljama en el pago de sendas capellanías de 250 y 150 s. a San Lorenzo y a la Catedral ${ }^{7}$. Posteriormente, a 12 de abril, Jucé paga a la priora y monasterio de Sijena tres s. de treudo por una casa en la judería en el barrio Marquesa de Fraga ${ }^{8}$. Con posterioridad a esa fecha, fallece. Así, en 20 de noviembre de 1401, «Dompna Bella Avinardut, judía Osce, uxore de Jucé Avinardut, físici, quondam» aparece prestando a Guillermo Vitalis, notario oscense, 600 s. ${ }^{9}$ y, de nuevo, el 2 de marzo de 1402 «Dona Bellya Avinardut [...] muller de maestre Juceff Avinardut físico de la senya reyna [...] qui fue», presta 1.000 s. a Martín de Liçana de Sessa para su mujer ${ }^{10}$.

No obstante, otra mención en 4 de julio de 1414 a «Dona Duenya d'Almalí», que dice ser «muller de maestre Jucé Avinardut, físigo [...] quondam», induce a pensar que podría tratarse de otra mujer del mismo Jucé ${ }^{11}$.

Coetáneo, y quizás pariente, del anterior es Mossé Abenardut («fisigo don Mussé»), hijo de Jucé, que en 1352 presta al Cabildo de la catedral 1.000 s. ${ }^{12}$.

La primera mención documental a HAYM ABENARDUT (2) se relaciona con su examen para «físico» en el año 1398. El 30 de agosto de 1403 Haym presta al moro Mahoma de Dona dos piezas de «panyos de la suert de Figueras» por 30

${ }^{4}$ AHPH, prot. 2875, f. ${ }^{\circ} 51$.

5 AHPH, prot. 7, f. 16.

${ }^{6}$ Cit. R. del Arco, «La aljama judaica de Huesca», Sef 7 (1947), págs. 271-301: 287. ACA, reg. 2113 , f. ${ }^{\circ} 55 \mathrm{v}$ y $70 \mathrm{v}$. La obligación de examen había sido aprobada en las Cortes de Monzón de 1363, en las que se había dictado una ordenación que obligaba a los judíos y musulmanes a ser examinados para ejercer la medicina. La prueba estaba presidida por un médico de su Ley y otro cristiano. En caso de que no hubiera ninguno judío o musulmán, debían presidirlo dos cristianos. El examen versaba «in arte medicine et fisici, sed etiam in metafisica, in naturi et in aliqua parte astrologie», cf. A. CARdoner i Planas, Història de la medicina a la Corona d'Aragó (Barcelona 1973), pag. 90.

7 AHPH, prot. 11095, f. ${ }^{\circ} 38 v-39$ r.

${ }^{8} \mathrm{AHPH}$, prot. 11095 , f. $^{\circ} 39$.

9 AHPH, prot. 3 , f. $^{\circ} 84$.

${ }^{10}$ AHPH, prot. 9960, f. $^{\circ} 38$.

${ }^{11} \mathrm{AHPH}$, prot. 373, f. ${ }^{\circ}$ 49. Carta de procuración por la que doña Dueña constituye por pr curadores suyos a «don Vidal de Almarrabí, físici Cesarauguste e Geudá Avinardut, fillo mío, Osce», apareciendo como testigos Pedro de Luesia y Açach Recopal.

${ }^{12}$ Cit. A. Durán Gudiol, La judería de Huesca (Zaragoza 1984), pág. 37. 
florines, con el compromiso de que se los pague en el mes de noviembre. Quizás la transacción ocultara otra finalidad, porque lo cierto es que este testimonio no nos permite afirmar que Haym fuera «mercadero en panyos» ${ }^{13}$. Sabemos que su madre «Bellya Avinardut, muller de don maestre Jucef Avinardut» había muerto antes del 24 de septiembre de $1405^{14}$. Como suele suceder a menudo, nos encontramos con menciones a homónimos, como otro Haym Avinardut, hijo de Jacob (¿hijo, a su vez, de Alazar rabí?), que en este mismo año, figura como testigo en una comanda suya ${ }^{15}$.

De su extensa actividad económica queda reflejo en la documentación notarial. Así, realiza un importante préstamo de 220 florines al «canonge» del castillo-convento de Montearagón que administra Quicena en marzo de 1407, y que refleja la dependencia económica de los pueblos del Abadiado. El préstamo será amortizado el 21 de julio de $1408^{16}$. Poco después, el 8 de septiembre de 1407, un albarán nos descubre sus relaciones familiares. En él, aparece como «heredero e sucesor universal ab intestato qui so de los bienes que fueron de Bellya Avinardut, muller, quondam, de maestre Jucé Avinardut, físigo de la senyora Reyna, judíos Huesca, padre e madre míos, atorgo seyer pagado de aquellos docientos sueldos que vos, Alfonso de Puértolas, clérigo racionero de San Salvador de Sariñena» ${ }^{17}$.

El 28 de febrero de 1408, nombra procurador suyo a su hijo Salomón ${ }^{18}$ y en este mismo año, en una comanda, figura como testigo Jucé Avinardut, hijo de Jacobo, judío de Huesca. En otra comanda, de 1445, aparece como testigo Haym Avinardut, hijo de Mossé Havinardut. A continuación, presento una relación de las comandas en las que Haym aparece como acreedor, y de las que ha quedado testimonio documental:

\begin{tabular}{lcrr}
\multicolumn{1}{c}{ NOMBRE DEUDOR } & LOCALIDAD & IMPORTE DEUDA & \multicolumn{1}{c}{ FECHA } \\
M. Nisano & Lierta & $400 \mathrm{~s}$. & 8 -VII-1403 \\
Mahoma de Dona & & 30 florines & 30 -VIII-1403 \\
Miguel de Navardun & Huesca & $50 \mathrm{~s}$. & $17-$ VII-1405 \\
Garcia de Apiés & Huesca & $100 \mathrm{~s}$. & $11-\mathrm{XI}-1405$
\end{tabular}

\footnotetext{
${ }^{13} \mathrm{AHPH}$, prot. 2875, f. $^{\circ} 43 \mathrm{v}$.

${ }^{14}$ AHPH, prot. 2884, f. ${ }^{\circ} 142$.

15 AHPH, prot. 251, f. ${ }^{\circ} 41$.

${ }^{16} \mathrm{AHPH}$, prot. 265 , f. $^{\circ} 13 \mathrm{v}$

17 AHPH, prot. 265, f. ${ }^{\circ} 52$.

${ }^{18} \mathrm{AHPH}$, prot. 15 f. $^{\circ} 22$.
} 


\begin{tabular}{|c|c|c|c|}
\hline NOMBRE DEUDOR & LOCALIDAD & IMPORTE DEUDA & FECHA \\
\hline Pedro Lucca & Velillas & $250 \mathrm{~s}$. & 12-VIII-1406 \\
\hline Sancho Cosculluela, vicario & Callén & $100 \mathrm{~s}$. & $1-\mathrm{I}-1407$ \\
\hline Anthón de la Segarra & Huesca & $50 \mathrm{~s}$. & 2-II-1407 \\
\hline Anthón de Palacio & Fraella & $200 \mathrm{~s}$. & 2-II-1407 \\
\hline Pedro Lapenya & Huesca & 8 quart. trigo & 7-II-1407 \\
\hline Pedro Lapenya & Huesca & 1 chz., 8 quart. tri. & 7-II-1407 \\
\hline Pedro Lapenya & Huesca & 5 arrobas trigo. & 7-II-1407 \\
\hline «Canonge» de Montearagón & Huesca & 220 florines & III-1407 \\
\hline Domingo Saliellyas & Alcubierre & $300 \mathrm{~s}$. & $2-V-1407$ \\
\hline Domingo Lafuent & Huesca & $1.000 \mathrm{~s}$ & $2-V-1407$ \\
\hline Domingo Sallliellyas & Alcubierre & $300 \mathrm{~s}$. & $3-V-1407$ \\
\hline Sancho Pérez & Aísa & $200 \mathrm{~s}$. & $22-V-1407$ \\
\hline Pedro Beltrán, rector & Ponzano & $2.000 \mathrm{~s}$ & 8-VIII-1407 \\
\hline Pedro Arruebo & Alcubierre & $100 \mathrm{~s}$. & 26-VIII-1407 \\
\hline Pedro Jurdán, notario & Poleñino & $120 \mathrm{~s}$. & 31-VIII-1407 \\
\hline Domingo Lorient & Alcubierre & $3.000 \mathrm{~s}$ & 18-XI-1407 \\
\hline Martín de Fanlo & Sangarrén & $1.200 \mathrm{~s}$ & 24-XI-1407 \\
\hline Sancho de Asilmell & Almudévar & $200 \mathrm{~s}$. & $15-\mathrm{I}-1408$ \\
\hline Pedro Lapenya & Lupiñén & $200 \mathrm{~s}$. & $4-V-1408$ \\
\hline Bernat de Soler & Huesca & $600 \mathrm{~s}$. & $24-V-1408$ \\
\hline Juan de Lierta & «Gramaet» & $500 \mathrm{~s}$. & 17-IX-1408 \\
\hline Juan de Corredor & Tardienta & $200 \mathrm{~s}$. & 2-IX-1408 \\
\hline Ramón de Boriamón & Arbaniés & $120 \mathrm{~s}$. & 24-IX-1408 \\
\hline Gill de la Siellya & Almudévar & $200 \mathrm{~s}$. & $20-\mathrm{XI}-1408$ \\
\hline Pedro Montaragón & Huesca & $700 \mathrm{~s}$. & $1-\mathrm{XI}-1408$ \\
\hline Blasco de Arbaniés & Sesa & $200 \mathrm{~s}$. & 29-XI-1408 \\
\hline Sancho Cosculluela, vicario & Callén & $200 \mathrm{~s}$. & 14-XII-1408 \\
\hline Arnalt de Laduca & Huesca & $300 \mathrm{~s}$. & 7-II-1409 \\
\hline Pedro Montaragón & Huesca & $200 \mathrm{~s}$. & 19-III-1409 \\
\hline Juan de Robres & Sesa & $200 \mathrm{~s}$. & $9-\mathrm{VI}-1409$ \\
\hline García Favana & Callén & $100 \mathrm{~s}$. & 9-VI-1409 \\
\hline Clemente Gentor, clérigo & Alcubierre & $200 \mathrm{~s}$ & 19-VII-1409 \\
\hline Marín de Sant Pero & Huesca & $107 \mathrm{~s}$. & $15-\mathrm{I}-1411$ \\
\hline Juan de Solana & Sesa & 20 florines & 11-III-1411 \\
\hline
\end{tabular}


LOS MÉDICOS JUDÍOS DE HUESCA

\begin{tabular}{|c|c|c|c|}
\hline NOMBRE DEUDOR & LOCALIDAD & IMPORTE DEUDA & FECHA \\
\hline Gullem Gastón & Boriaman & $132 \mathrm{~s}$. & 12-VI-1411 \\
\hline Pero Gros & Sesa & $120 \mathrm{~s}$. & 12-VI-1411 \\
\hline Juan de Val & Sesa & $263 \mathrm{~s}$. & 3-VII-1411 \\
\hline Domingo Pérez Bonanat & Huesca & $1.300 \mathrm{~s}$ & 20-XI-1411 \\
\hline Pedro Nisano, vicario & Lupiñén & $500 \mathrm{~s}$. & 20-XI-1411 \\
\hline Justo de Gabino & Almudévar & $900 \mathrm{~s}$. & $18-\mathrm{I}-1415$ \\
\hline$[¿ ?]$ de Lizana & Huesca & $100 \mathrm{~s}$. & 5-II- 1415 \\
\hline Juan de Corredor & Zuera & $200 \mathrm{~s}$. & 16-IV-1415 \\
\hline Juan de Tabernas & Almudévar & $300 \mathrm{~s}$. & $18-\mathrm{XII}-1444$ \\
\hline Martín de las Cañas & Almudévar & $120 \mathrm{~s}$. & 2-XII-1445 \\
\hline Martín de Fabana & Almudévar & $120 \mathrm{~s}$. & $16-X I I-1445$ \\
\hline Juan de $[i ?]$ & Almudévar & $300 \mathrm{~s}$. & 30-III-1446 \\
\hline Domingo de Nasarre & Almudévar & $72 \mathrm{~s}$. & 31-III-1446 \\
\hline Martín de Nocito, clérigo & Almudévar & 24 florines & $13-\mathrm{XI}-1446$ \\
\hline Antón de Alquézar & Almudévar & 18 florines & $13-\mathrm{XI}-1446$ \\
\hline Pedro de Alcamarín & Almudévar & $110 \mathrm{~s}$. & 23-XII-1446 \\
\hline Martín de [i?] & Grañén & $285 \mathrm{~s}$. & 2-XI-1447 \\
\hline Juan de Andués & Alcalá de Gurrea & $530 \mathrm{~s}$. & 13-IX-1448 \\
\hline Martín de Callén & Torralba & $76 \mathrm{~s}$. & $18-\mathrm{XI}-1448$ \\
\hline Mateo de Pedro & Plasencia & $50 \mathrm{~s}$. & 26-VIII-1451 \\
\hline Juan de López & Igriés & $100 \mathrm{~s}$. & 13-XII-1451 \\
\hline Juan de Bolea & Torralba & $70 \mathrm{~s}$. & 8-III-1452 \\
\hline Vicente Ferrer & Sesa & 2 chzs. trigo & 22-IV-1452 \\
\hline Pedro de Escuer & Tardienta & $31 \mathrm{~s}$. & 22-II-1455 \\
\hline
\end{tabular}

Tal como se puede observar en la anterior relación, la distribución geográfica de los préstamos está muy determinada por la proximidad a la ciudad de Huesca, siendo Alcubierre el lugar más lejano de residencia de un prestatario. En buena parte de los casos, se trata de cantidades altas de capital prestado en cada operación, préstamos expresados, casi siempre, en moneda, y sólo unos pocos en cereal que, probablemente, se pagarían con los beneficios de la cosecha. Por otro lado, llama la atención el vacío de los años 1416-1443, en los que no se registran préstamos, y que coincide con la presencia activa de Jucé Avinardut, yerno de Haym. Los años 1407 y 1408 son los que registra Haym mayor cantidad de préstamos; por el contrario, en otros años sólo se registra un préstamo o poco 
más. El mismo Haym es receptor de préstamos en 1405 (400 s.), 1430 (800 s.) y 1436 (100 s.).

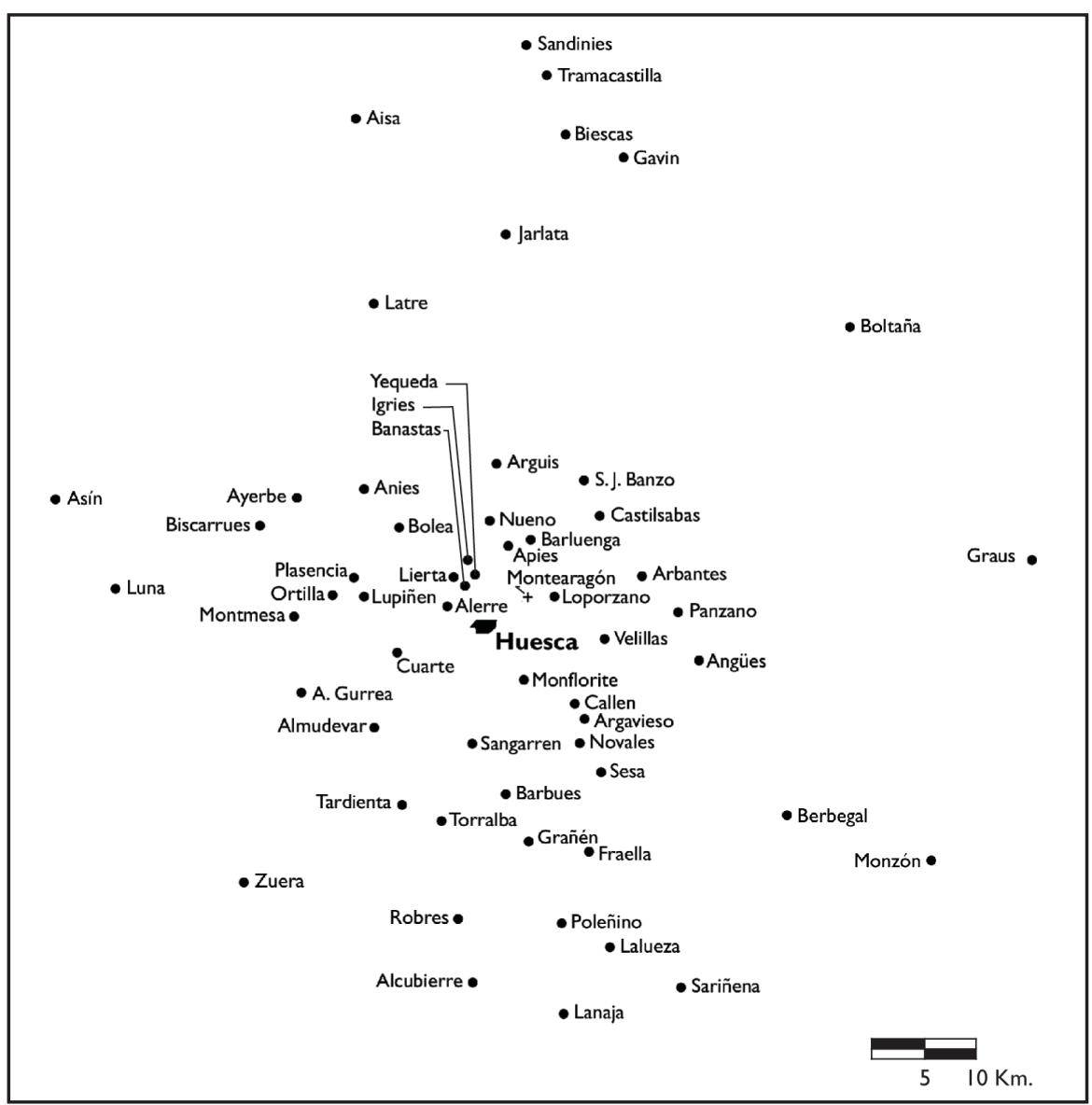

Localidades de origen de prestatarios de judíos de Huesca. Croquis indicativo.

(C) E. Benedicto Gracia y EDDG-CCHS, CSIC.

El 10 de abril de 1409, Haym encargaba dos tumbas al «piquero» oscense Bernat del Soler, una para su padre y otra para su madre. Estas tumbas se encontraban en el «fosal nuevo». Desde el siglo XII hay noticias de que el cementerio judío se localizaba junto a San Jorge, camino de Loreto. No obstante, desconozco la cercanía de este nuevo cementerio al barrio judío. Las tumbas encargadas se componían de los siguientes elementos: una solera de sillares colocados más hondos que la línea de tierra; sobre ellos, una caja de piedra que unía los sillares de la solera y, encima de esta capa, la losa, quedando todo ello unido con mor- 
tero de cal y arena. Su medida aproximada era de $2,41 \mathrm{~m}$ de largo por $0,84 \mathrm{~m}$ de ancho (Apéndice, doc. $\left.n^{\mathrm{o}} 1\right)^{19}$.

El 25 de septiembre de 1411, en pleno periodo de interregno, los mercaderes Domingo Pérez Bonanat y Aznar de Bolea se obligaban en 1.300 s. por un préstamo de Haym, a pagar el día de Todos Santos del año siguiente, poniendo como aval unas casas situadas en el barrio de Campaneros (hoy, calle de Santiago). Jacob Avinardut aparece como testigo del acto, junto con Sancho Burro y Jayme d'Aínsa, clérigos beneficiados de la Seo de Huesca. A continuación, Domingo daba a loguero a Haym por un año unas casas, que se supone son las que figuran en el aval, por $150 \mathrm{~s}$. jaqueses, pudiendo, bajo ciertas condiciones, prorrogar el alquiler por más tiempo del pactado. El hecho de que un judío pudiera habitar en el centro de la ciudad, fuera de la judería, es excepcional, ya que no conozco ningún otro caso en la documentación disponible, y podría responder al interés de los cristianos de tener cerca, día y noche, a un médico judío (Apéndice, doc. $\mathrm{n}^{\mathrm{o}} 2$ ).

Por otro documento posterior, Haym se responsabilizaba de la compra de 364 litros de aceite que efectúa Manuel Minel a maestre Gil, cubriendo las pérdidas que la renuncia a la compra por aquél produjera a éste, aunque desconocemos si hay que deducir de ello algún tipo de sociedad entre ambos ${ }^{20}$.

En cuanto a su actividad pública sabemos que en mayo de 1444 es nombrado procurador por la aljama ${ }^{21}$. Su fallecimiento se produce con anterioridad a 11 de junio de 1455, ya que en esa fecha, su hija Estrellya cancela una comanda contraída por su padre ${ }^{22}$.

Otro destacado miembro de esta familia es el yerno del anterior, maestre Jucé Abenardut «menor» (3), físico e hijo de Salamón. Como clavario o tesorero de la aljama, está encargado de entregar en 1405 dos treudos de 5.000 s. y 400 s., respectivamente ${ }^{23}$. Años más tarde, en 1409, Jucé alquilaba unas casas como regidor que era, junto con Daví Fanoca, de la cofradía de «Haverin» ('de los compañeros') ${ }^{24}$.

${ }^{19}$ Se trata de la única descripción detallada de una tumba judía en la documentación revisada. En otros casos, se alude a la copia, por el «piquero» de otras tumbas ya existentes.

20 AHPH, prot. 177 , f. $^{\circ} 208 \mathrm{v}(18-\mathrm{X}-1425)$.

${ }^{21} \mathrm{AHPH}$, prot. 83, f. ${ }^{\circ} 154$.

${ }^{22}$ AHPH, prot. 89 , f. $^{\circ} 60$.

${ }^{23} \mathrm{AHPH}$, prot. 2884, f. ${ }^{\circ} 110 \mathrm{v}$ (21-VI-1405) y prot. 2884, f. 18 (9-VII-1405).

${ }^{24} \mathrm{AHPH}$, prot. 277, f. 9v, 1-II-1409: «Jucef Avinardut físsico e Daví Fanoca, regidores de la cofradía Hauerín, alias de los companyeros de la judería de Huesca [...] reciben unas casas en la judería, por precio de 650 sueldos [...] por anyo». 
Quizás alguna responsabilidad religiosa, como la citada anteriormente, explica que recibiera el 29 de julio de 1427, de Blanqa Beltrán, viuda de Alfonso Gómez «el Franquo», un asiento donde «se posan las mulleres al tiempo que fazen oración en la sinoga, clamada el Palaçuela», de la que la dicha Blanqa le hacía gracia ${ }^{25}$.

El 29 de junio de 1428 Jucé, que debía ocupar un puesto eminente en la aljama, se presenta ante el jurado y el justicia para reclamar que se cumpliera lo establecido en el Estatuto de la ciudad que prohibía a los forasteros portar armas por la ciudad y que, además, transitaran por la aljama, al ser una amenaza para los judíos que, como dice Jucé, eran «regalías del senyor rey» (Apéndice, doc. $n^{\circ} 4$ ). Su responsabilidad al frente de la aljama no se acaba aquí, ya que en 1430 y 1432 es mencionado como clavario y adelantado. A continuación, damos una nómina de las comandas realizadas por Jucé, cuya extensión geográfica es similar a las de las realizadas por su suegro Haym.

\begin{tabular}{|c|c|c|c|}
\hline NOMBRE DEUDOR & LOCALIDAD & IMPORTE DEUDA & FECHA \\
\hline Martín Ballesteros & Huesca & $160 \mathrm{~s}$. & $6-X-1426$ \\
\hline Martín Ballesteros & Huesca & $140 \mathrm{~s}$. & $23-X-1426$ \\
\hline Lorenzo de Mont & Robres & $180 \mathrm{~s}$. & 4-XI-1426 \\
\hline Lorenzo de Binarch & Huesca & $50 \mathrm{~s}$. & 25-VIII-1428 \\
\hline Jaime de Pano & Almudévar & $100 \mathrm{~s}$. & 26-VIII-1428 \\
\hline Juan de Peñafiel & Almudévar & $120 \mathrm{~s}$. & 15-IX-1428 \\
\hline Miguel Diese & Banastás & 8 florines & $30-$ III-1429 \\
\hline Martín de Aguas & Almudévar & 12 florines & 13-IV-1429 \\
\hline Miguel Diese & Banastás & $80 \mathrm{~s}$. & $3-V-1429$ \\
\hline Juan de Ferrer & Huesca & 10 florines & $27-X-1429$ \\
\hline Juan Galino & Banastás & $62 \mathrm{~s}$. & $16-$ II- 1432 \\
\hline Juan de Eyerbe, clérigo & Huesca & $35 \mathrm{~s}$. & 26-VII-1432 \\
\hline Asensio San Martín & Huesca & $60 \mathrm{~s}$. & s. d. ¿1433? \\
\hline Domingo Asvero & Alcubierre & 8 florines, $18 \mathrm{~s}$. & s. d. ¿1433? \\
\hline
\end{tabular}

Una carta de 10 de mayo de 1434 nos describe la causa de la muerte de Jucé en el monasterio mercedario de Santa María de Monflorite (a unos $5 \mathrm{~km}$ al sur

${ }^{25}$ AHPH, prot. 11097, f. ${ }^{\circ} 7$ (29-VII-1427): «Blanqua Beltrán, muller del honorable Alfonso Gómez, el Franquo, quondam, da a rabí Jucef Avinardut, físico, judío, los logares o sitios do se posan las mulleres al tiempo que fazen oración en la sinoga de las mulleres [...] clamada el Palaçuela». 
de Huesca). El cura Johan Lóppez de Gurrea, merino de Huesca, había mandado a Pero Pardo, escudero y lugarteniente de merino, ya que si bien se decía que la mula de Jucé lo había matado, el oficial estaba obligado a averiguar la causa real de su muerte para imponer la multa por homicidio. Como finalmente la multa no se pudo imponer, el oficial tomó la mula, devolviéndola a los familiares del médico difunto. Desconocemos si, al igual que sucedió en otras ocasiones, se iniciaron las pesquisas para encontrar al culpable de su muerte, pero parece que bastó con el testimonio de los frailes del monasterio (Apéndice, doc. n. ${ }^{\circ}$ 6). Pocos meses después, el 5 de julio de 1435, encontramos a «Duenya Avinardut, muller de Haym Avinardut e Reyna, muller de Jucef Avinardut, [...] como herederos de los bienes de rabí Jucef [... que] reciben cient sueldos [...] de comanda del dito rabí Jucef, según carta de XXIX de mayo de $\mathrm{M}^{\circ} \mathrm{CCCC}^{\mathrm{o}}$ vicésimo sexto» ${ }^{26}$.

El último físico de esta familia documentado en los protocolos es Astruch Avinardut, alias Cohén (4), que figura como testigo en la venta de una «biesa» (pequeño trozo de terreno) propiedad del monasterio de Sijena, el 9 de octubre de 1457, que Mossé Ardit vende a Acach Zuri ${ }^{27}$. En 1458, Astruch forma parte de la aljama, siendo elegido en 1474 dayán por la mano mayor, y en la insaculación de 1478, dayán por la mano mayor, aunque en esta última fecha es «repulso» por haber fallecido ya ${ }^{28}$. Su viuda, Strellya Benardut, dice que su hijo es «apotecario», y casado con Bonadona Alintienz, siendo el único caso registrado como apotecario judío que se cita en la documentación oscense ${ }^{29}$.

La primera referencia a maestre Astruch CAVATIERRa (5) que poseemos está fechada en 13 de noviembre de 1407. Ese día, Astruch aparece debiendo 120 s. a Palacín Baraca ${ }^{30}$. Hasta el 17 de marzo de 1428 no volvemos a tener noticia suyas. En esa fecha vendía a Johan de Marco una viña en el término de «Conillyenegue» ${ }^{31}$. El 16 de marzo de 1434, Astruga Havinbitas, viuda de Astruch Cavatierra, «cilúrgico», Açach Cavatierra, «cilúrgico», la muger de

${ }^{26} \mathrm{AHPH}$, prot. 287, f. ${ }^{\text { }}$ 40v. Haym había recibido también otra comanda de su yerno Jucef, por valor de 30 florines. Y en 21 de febrero de 1446, Jamila Havinardut, hija de Jeudá Havinardut, judío de Huesca, dice ser mujer de Jucé, judío, «físiqo quondam», AHPH, prot. 189, f. 2 22v.

${ }^{27}$ AHPH, prot. 63, f. ${ }^{\text {o }} 79$.

${ }^{28}$ Cf. mi «Documentos acerca del funcionamiento del sistema de insaculación en la aljama judía de Huesca (siglo Xv)», Sef 66 (2006), págs. 309-344: 320 y 324.

${ }^{29} \mathrm{AHPH}$, prot. 318 , f. $^{\circ} 120 \mathrm{v}$.

${ }^{30} \mathrm{AHPH}$, prot. 2884, f. ${ }^{\circ} 70 \mathrm{v}$.

${ }^{31}$ AHPH, prot. 181, f. $^{\circ}$ 51r. 
éste, Duenya Havinbitas, junto con Jehudá Cavatierra, «cilúrgico», reconocían tener 500 s. en comanda de Violant de Santa Fe, viuda del converso don maestre Jayme de Santa Fe, que devuelven el 14 de agosto de $1441^{32}$.

Otro médico, Açach Cavatierra (6) aparece testificando en una comanda de Simuel Hanín, judío de Huesca, el 5 de febrero de $1428{ }^{33}$. Este mismo, junto con Simuel Iriça y Simuel Gastón, judíos de Huesca, tienen una comanda de $550 \mathrm{~s}$. de Violant de Santa Fe, que han de pagar en cinco años ${ }^{34}$. Es posible que Açach se convirtiera, y que a consecuencia de ello vendiera el 16 de marzo de 1434 a su madre y a su hermano Jehudá, «cilúrgico», un tercio de sus casas, contiguas a las de su familia, y todos sus bienes por 150 florines de oro ${ }^{35}$. Sin embargo, aún en 1436 el mercader Johan de Amellas eximía de culpa a Açach de ciertos «furtos» que comprobaba que aquél no había cometido (Apéndice, doc. $\mathrm{n}^{\circ}$ 7). Años más tarde, en 1441 Violant de Santa Fe entregaba a maestre Ramón Onzina, «olim clamado Açach Cavatierra, cirúrgico», el albarán de 500 s. que toda la familia venía debiendo desde 1434 (Apéndice, doc. $\mathrm{n}^{\circ}$ 9).

La documentación no diferencia claramente entre otros dos médicos homónimos, padre e hijo, de nombre JehudÁ CAVATIERRa (7-8). Encontramos bastantes referencias a ambos. De ellas, selecciono las que pueden presentar mayor interés documental. Un Jehudá es citado por el merino de Huesca en 1428 para testimoniar acerca de la muerte de Bernat de Aspa (Apéndice, doc. $\mathrm{n}^{\circ}$ 5).

El 8 de mayo de 1444, uno de los dos, quizás el padre, es citado como adelantado de la aljama de Huesca. Décadas más tarde, el 28 de septiembre de 1481, su homónimo aparece también citado como adelantado de la aljama. La participación en cargos directivos de la aljama no se reduce a estas dos escuetas referencias. Sabemos que en abril de 1471, el «mayor» es elegido dayán por la mano mediana y menor, y el hijo es elegido adelantado. Pocos días después, ambos resultan elegidos respectivamente, dayán y consellero por la mano mediana ${ }^{36}$. Su protagonismo en cargos directivos de la aljama puede explicar que uno de ellos aparezca mencionado en 19 de agosto de 1458, como garante de un censal contraído por la aljama.

\footnotetext{
32 АНPH, prot. 181, f. ${ }^{\circ}$ 51r.

$33 \mathrm{AHPH}$, prot. 11763 , f. ${ }^{\circ} 5 \mathrm{v}-6 \mathrm{r}$.

${ }^{34}$ AHPH, prot. 181, f. ${ }^{\circ} 106 \mathrm{v}$ (1-VIII-1431).

35 AHPH, prot. 181, f. ${ }^{\circ} 51 \mathrm{v}$.

${ }^{36}$ Benedicto Gracia, «Documentos acerca del funcionamiento del sistema de insaculación»,
} págs. 329-332. 
Otros testimonios documentales son de contenido muy variado. Así, el 13 de junio de 1428, Jehudá testifica en una comanda de Mossé Adida ${ }^{37}$. Quizás se trate del mismo Mossé Adida, de cuyos hijos es tutor un Jehudá Cavatierra en 1 de julio de 1465. Por otro lado, el 30 de agosto de 1447, Jehudá Cavatierra recibe una casa en alquiler en el barrio Almalbel. Posiblemente sea el hijo el que en 17 de octubre de 1480 le da poderes para la reventa de unas casas en Huesca (Apéndice, doc. $\mathrm{n}^{\circ}$ 16). Por último, el 7 de julio de 1481 Jehudá Cavatierra es testigo en una comanda de rabí Jucé Papur ${ }^{38}$.

A Sentó Cavatierra (9) «maestre en medicina» pertenece el primer documento de curación que se ha conservado en los protocolos notariales. Se trata de una comanda que Anthón de Sangüesa, paciente de Huesca, contraía en 1440 con este médico por un importe de ocho florines de oro. Por ese contrato, aquel se comprometía a curar a Anthón de una úlcera que tenía en la pierna derecha, con la condición de que siguiera el «regimiento» que le impusiera. Está claro que el importe de la curación se pagaba mediante una comanda (Apéndice, doc. 8).

$\mathrm{Al}$ igual que con otros médicos oscenses, se conservan referencias a su actividad crediticia centrada en la Hoya de Huesca, y de las cuales reseño las siguientes:

\begin{tabular}{llrr}
\multicolumn{1}{c}{ NOMBRE DEUDOR } & \multicolumn{1}{c}{ LOCALIDAD } & IMPORTE DEUDA & \multicolumn{1}{c}{ FECHA } \\
Bernart Colín & Huesca & $170 \mathrm{s.}$ & $2-\mathrm{IV}-1451$ \\
Vicente Ferrer & Sarsa & $250 \mathrm{~s}$ & $4-\mathrm{IV}-1451$ \\
Calema Antillyón & Barbués & $275 \mathrm{s.}$ & $27-\mathrm{V}-1451$ \\
Miguel de Ernialde & Huesca & $100 \mathrm{~s}$. & $15-\mathrm{XII}-1451$ \\
Pedro Latrás & Yéqueda & $58 \mathrm{s.}$ & $15-\mathrm{X}-1457$ \\
Miguel de Ordás & Huesca & $92 \mathrm{s.}$ & $23-\mathrm{II}-1458$ \\
Juan de Formester & Huesca & $63 \mathrm{~s}$. & $4-\mathrm{V}-1458$ \\
Juan de Aperet & Huesca & $30 \mathrm{s.}$ & $20-\mathrm{XI}-1458$ \\
Martín de Samper & Huesca & $110 \mathrm{s.}$ & $7-\mathrm{II}-1471$ \\
Martín de Aisa & Huesca & $110 \mathrm{s.}$ & $7-\mathrm{XI}-1475$
\end{tabular}

${ }^{37}$ АHPH, prot. 11763 , f. ${ }^{\circ} 18 \mathrm{r}$.

${ }_{38} \mathrm{AHPH}$, prot. 318, f. ${ }^{\circ} 143 \mathrm{v}-144 \mathrm{r}$ : «Comanda de don rabí Jucé Papur, judío Osce. Sea man fiesto a todos que nos, Antona del Río [...] tener en comanda de vos [...] a ssaber onze cafizes de trigo bueno, limpio, mercadero [...] Testes: Gil de Pueyo, vezyno del dito lugar de Lopinyén et maestre Jehudá Cavatierra, fillyo de maestre Jehudá, Osce». 
El 12 de enero de 1461, Sentó entregaba a Martín d'Stronat, escudero de Plasencia, dos cahíces de cebada a «metadería», para sembrarla en buena tierra, debiendo pagar Sentó la mitad de las «spensas» de segar teniendo derecho a recibir la mitad de la cosecha. Acuerdos como este eran muy corrientes y se realizaban tanto en agricultura como en ganadería ${ }^{39}$. En 1474 Sentó Cavatierra era elegido dayán por la mano mediana y menor ${ }^{40}$.

Es relativamente frecuente encontrar entre los protocolos notariales «cartas públicas de muerte». Una de ellas, la de Sentó Cavatierra en 1475, en la que el notario Blasco Colduras nos describía la escena funeraria tras el fallecimiento de Sentó, con plañideras incluidas: «[...] dentro un palacio [...], en derredor de un scanyo [féretro con andas], stavan muytas duenias judías plorantes [...]». El hijo de Sentó había pedido al notario que le hiciera carta pública del fallecimiento, necesaria para justificar ante las autoridades su muerte, y a efectos de herencia entre sus deudos (Apéndice, doc. $\mathrm{n}^{\mathrm{o}} 15$ ). $\mathrm{Al}$ año siguiente, ya fallecido, Sentó era elegido adelantado de la aljama por la mano mayor, según el sistema de insaculación, aunque dicha elección quedaba inhábil por su deceso ${ }^{41}$.

Otra familia destacada dentro de la aljama judía de Huesca es la de maestre Mossé ARRONDí (10). La primera mención a este médico es en una comanda por la que presta a Mahoma Moriel siete cahíces y veintiún cuartales de trigo ${ }^{42}$. Su viuda Bellya Benardut contrae en 1475 una deuda con un mercader por importe de 117 s. Un año más tarde, ella misma vende a Violant de Alcolea de Huesca, la mitad de unas casas en el barrio de San Cebrián ${ }^{43}$.

Más interés aún presenta rabí AÇACH ARRONDí, hijo del anterior ${ }^{44}$. Ya en 1442, una sentencia arbitral emitida por Mossé Argellet condena a la aljama a pagarle 140 florines (Apéndice, doc. $\mathrm{n}^{\circ}$ 10). Parece que con los años sus relaciones con otros judíos, en especial con alguna de las facciones dominantes de la aljama no serían fluidas, y de todo ello ha quedado testimonio documentado en los protocolos notariales. Así, por ejemplo, en 1447 Sentó Ambrón y su madre Bellyta

39 AHPH, prot. 96, f. 17.

${ }^{40}$ AHPH, prot. 155, f. 7 v. En 1475, Sentó figura en la lista de «casatenientes» judíos de Huesca, cf. E. Benedicto Gracia, «La aljama de los judíos de Huesca a fines del siglo xv: una nómina de casatenientes de la judería de 1475», Sef 63 (2003), págs. 227-236: 233, nº 29.

${ }^{41}$ AHPH, prot. 232, f. ${ }^{\text {7 }} 77 \mathrm{v}$.

${ }^{42}$ AHPH, prot. 93, f. ${ }^{\circ}$ 156v (7-V-1455).

${ }^{43}$ AHPH, prot. 312 f. $^{\circ} 135$.

${ }_{44}$ Tal como se precisa en una deuda por valor de 117 s. contraída en 1475 por él y por su madre, en AHPH, prot. 312, f.o 135. 
Moriel le reclamaban haber abierto una puerta y una ventana en su propiedad. La carta pública tiene un gran interés porque nos permite situar el «banyo» cerca de la «sinoga mayor» de la aljama (Apéndice, doc. $\left.\mathrm{n}^{\mathrm{o}} 11\right)^{45}$. El mismo rabí Açach es nombrado en 23 de septiembre de 1443, junto con Haym Avinardut, para arbitrar una sentencia acerca del pleito entre Lázaro Bonanat y Acah Avinardut ${ }^{46}$.

Años más tarde, en 1466, el rey Juan obligaba desde Fraga a los adelantados de la aljama oscense a dar el «oficio» de rabino a maestre Isach: «que por algunas differencias que entre vosotros son stadas, teniendo votos diversos en el dicho officio [...], por tanto, vos decimos e mandamos tant strechament como podemos, que de continent [...] déys el dicho officio al dicho Isach Arrundí». Con anterioridad, había sido designado para dicho oficio un «rabí strangero» cuya identidad desconocemos, designado por la aljama, pero a la que el rey ordenó que cesara de inmediato en el desempeño de su oficio «e aquesto por res mudades o differades en alguna manera» ${ }^{47}$.

Rabí Açach aparece citado como testigo en varios albaranes de la aljama, donde es tratado como «mege» y «don maestre» ${ }^{48}$. Finalmente, la obligación contraída en 1488 con rabí Açach por Guillyem de Casabona, pastor de Lupiñén, nos permite conocer un segundo contrato de curación. El acuerdo es distinto al anteriormente citado, que estaba compuesto de una comanda a la que seguía el compromiso. En este caso, el médico se comprometía ante notario a curar al pastor, teniendo que dar un médico cristiano el visto bueno. El coste del contrato asciende a $25 \mathrm{~s}$. (medicinas), además de 64 s. (tratamiento). En caso de que la curación no se realizara en el plazo acordado, Açach no cobraría, y si Casabona abandonara el tratamiento, debería pagar la cantidad fijada (Apéndice, doc. $\mathrm{n}^{\circ}$ 19).

Parece que Açach estaría implicado con otros judíos en el asunto de la circuncisión de Juan de Ciudad a comienzos de 1489, inmediatamente cas-

${ }^{45}$ AHPH, prot. 86, f. ${ }^{\circ}$ 19r-v; las casas de maestre Ysach Rondí estaban situadas también cerca de la «sinoga mayor»; quizás a estas casas se refiera la compra de media casa que Ysach hace a Duenya Abenardut en 24-V-1443, en AHPH, prot. 40, f. 24.

${ }^{46}$ AHPH, prot. 82, f. ${ }^{\circ}$ 283: «[...] sobre los bienes mobles y sedentes que fueron de Jehuda Avinardut, judío quondam, de Huesca, levaron las ditas cosas, questiones en poder de maestre Ysarch Rondí e maestre Haym Avinardut, meges Osce [...]».

${ }^{47}$ ACA, Cancillería, reg. 3373, f. ${ }^{\text {7 } 79 v}$ (10-XII-1466). El documento fue publicado por F. BAER, Die Juden im Christlichen Spanien. Urkunden und Regesten. Aragonien und Navarra (Berlin 1928), doc. $n^{\circ} 547$.

${ }^{48}$ Y realizando préstamos a Juan de Puértolas, de Grañén, por valor declarado de $240 \mathrm{~s}$. (10-v-1481); a Martín de Belsué, de Igriés, 81 s. (17-IX-1481), y a Juan Martínez, de Aniés, 32 s. (27-II-1486). 
tigada por la Inquisición ${ }^{49}$. Sin embargo, el 21 de julio de 1490, Açach está aún vivo, según demuestra la licencia que los jurados de Huesca le conceden para que lleve el agua de la acequia mayor a su huerto, en el barrio de Salcedas (Apéndice, doc. $\mathrm{n}^{\circ}$ 20). ¿Se salvó de recibir el mismo castigo que otros condenados a muerte?

Cuatro médicos llevan el apellido Cap. En opinión de Baer, la familia Cap procedía de Barcelona, y a ella habían pertenecido destacados mercaderes, llegando a ser uno de sus miembros, Ishac Cap, juez y dirigente de dicha aljama catalana ${ }^{50}$. Uno de los médicos oscenses es VIDAL CAP (12), «mege» ${ }^{51}$, el cual devuelve en 1456 a Lázaro Bonanat una correa de plata, quizás como aval de un préstamo ${ }^{52}$. Varios documentos mencionan su actividad crediticia entre 1447 y $14588^{53}$. Aún en 1465 figuraba en la nómina de prestamistas que realizaban la jura. Alguno de los testimonios refleja conflictos con otros judíos. Así, el 11 de junio de 1473, Jacó Xuén declaraba ante el lugarteniente del Justicia y el prior que, estando él enfermo y su mujer ausente, había encargado la custodia de su casa a maestre Vidal Cap. Éste, siempre según el testimonio de Jacó Xuén, abusando de su confianza y de acuerdo con un mozo, le habría robado joyas y prendas de valor. El documento describe sencillamente, pero con precisión, toda la actuación de Vidal y de Perfet, su hermano, los cuales, después del robo, se refugiarían en Montearagón donde pactarían la devolución de lo robado. Sería interesante saber por qué se refugiaron en Montearagón y cuál había sido la confianza que Vidal había tenido con los clérigos del monasterio (Apéndice, doc. $\mathrm{n}^{\circ} 14$ ).

De otros individuos de esta familia, apenas tenemos datos individuales. De AÇACH CAP (13), «físico» y «mege», sabemos que obtiene la licencia de medicina en Tárrega el 7 de octubre de $1469{ }^{54}$. Por su parte, Jucé CAP (14), la obtiene en $1472{ }^{55}$. SALter CAP «mege» (15) aparece mencionado como

${ }^{49}$ Y. F. BAER, Historia de los judíos en la España cristiana, [traducción de J. L. Lacave], (Madrid 1981), págs. 818-819.

${ }^{50}$ BAER, Historia de los judíos en la España cristiana, págs. 235, 274, 345.

${ }^{51}$ Según documento fechado en 15-XI-1456.

52 AHPH, prot. 195, f. 122 (11-VII-1456).

53 A Juan, notario de Huesca, 125 s. (6-I-1447); a un racionero de la Seo de Huesca, 155 s. (16-III-1451): al moro de Huesca Aljaffat, zapatero, 94 s. (19-XII-1451); a Ximeno Parroch de Huesca, 54 s. (20-I-1456); y a Abrayme, moro de Novales, 47 s. (7-IX-1458).

${ }^{54}$ ACA, reg. 3450, f. ${ }^{\text {4 } 42-43 v . ~}$

55 ACA, reg. 3455, folio antiguo 156 bis. (agradezco al Sr. J. Riera i Sans su amabilidad al facilitarme esta referencia documental y la anterior). 
testigo de la cancelación de una comanda de Jucé Xuén el 21 de diciembre de 1479 .

Abram Bivag (16) es el miembro más representativo de su familia; como médico y estudioso de la Ley había adquirido gran prestigio en la aljama; fue un estudioso profundo de los fundamentos de la fe y la razón, como refleja en su obra Dérej ha-emuná ('La senda de la fe'). Ciñéndome a la evidencia documental conservada en los protocolos notariales, la primera noticia que se refiere a él es de 7 de marzo de 1456, en que aparece citado como testigo en una comanda ${ }^{56}$. Años más tarde, el 3 de febrero de 1466, aparecía citado como intermediario entre los maestres Miguel de Jaca y Ximeno Pançano de Huesca, para la entrega del Canon de Avicena, texto de uso imprescindible para el estudio de la medicina aún en el siglo XV, ya que compendiaba lo que todo profesional de la salud debía conocer. Cabe la posibilidad de que la entrega oculte la venta del Canon a Ximeno, de la que Abram obtendría algún beneficio (Apéndice, doc. no 12) ${ }^{57}$.

Su situación económica no debía de ser muy buena, pues en 1469 se registra la venta de un huerto suyo, y en 1470 se consignan tres deudas suyas de 860, 533 y 1070 s. respectivamente. En otra carta pública de 14 de abril de 1470 aparece reclamando a la mujer de Johan de Cuenqua la comparecencia de éste y, al no producirse, él le reclama a ella el «pastel» que debía haberle entregado en marzo. El «pastel» mencionado, obtenido de las hojas del glasto, proporciona un colorante azul usado en tintorería (Apéndice, doc. $\left.\mathrm{n}^{\mathrm{o}} 13\right)^{58}$. En 1471 figura como adelantado de la aljama, siendo elegido consellero por la mano mayor y contador ${ }^{59}$. En opinión de Baer, habría fallecido antes de 1489.

De AçACH BıVACH (17), hermano del anterior, apenas tenemos noticias. Açach, médico también, habría estado implicado en el asunto de la circuncisión de Juan de Ciudad. Antonio Durán reproduce íntegramente su famosa confe-

${ }^{56}$ Es el mismo año, 1456, en que obtiene en Barcelona la licencia médica; cf. ACA, reg. 3295, f. $172 \mathrm{v}$.

57 El libro primero contenía los fundamentos de la ciencia médica, la fisiología y la anatomía, así como los principios generales en los que se basaba la patología y la terapéutica del galenismo. El segundo libro estaba dedicado a los simples. El tercero trataba de las fiebres, del conjunto de formas de enfermar y, también, de cirugía; finalmente, el libro quinto estaba dedicado a la farmacología práctica. Cf. L. GARCía BALLESTER, La búsqueda de la salud (Barcelona 2001), págs. 253-254.

${ }^{58} \mathrm{AHPH}$, prot. 308, f. ${ }^{\circ}$ 52. Otra escritura de 1470 registra una comanda que Abram tiene de Anthón Bonifant de $1.060 \mathrm{~s}$.

59 Benedicto Gracia, «Documentos acerca del funcionamiento del sistema de insaculación», págs. 329-332. 
sión ${ }^{60}$. Aparte de ello, apenas unos documentos de protocolos lo citan como testigo en varias transacciones en la década de $1480{ }^{61}$. Lo mismo pasa con el «mege» («meche») GENTó Bivach (18) del que sólo tenemos unas pocas referencias documentales de la segunda mitad de la década de $1450{ }^{62}$.

De los médicos de la familia Avendet, solamente tenemos información económica relativa a comandas realizadas. Así, de JucÉ Avendet (19), «don maestre mege» según el testimonio de una comanda de 1476, tan sólo se testimonia una comanda de $100 \mathrm{~s}$. y un cahíz de trigo. La actividad crediticia de EZMEL Avendet (20), «maestre» o «mege», indistintamente, aparece recogida con más detalle en los protocolos. En 1477 Ezmel había sido elegido adelantado de la aljama por la mano mediana ${ }^{63}$. Los préstamos realizados por éste, en su inmensa mayoría, se limitaban a lugares de la Hoya de Huesca y, excepcionalmente, del Valle de Tena. Además de préstamo en moneda, hay cierta abundancia de préstamos en especie (cereales y aceite). Especialmente llamativa es la cuantía del préstamo de 100 cahíces de trigo al concejo de Grañén. A continuación, proporcionamos una lista de las comandas registradas a su nombre:

\begin{tabular}{|c|c|c|c|}
\hline Nombre Deudor & LoCALIDAD & IMPORTE DEUDA & Fесна \\
\hline Ramón de Andans & Grañén & 100 s., 1 chzs. trigo & 28-III-1475 \\
\hline Martín de Aquilué & Grañén & 100 s., 1 chzs. trig & 28-III-1475 \\
\hline Juan de Bastarás & Huesca & $39 \mathrm{~s}$. & 25-IV-1475 \\
\hline Juan Pastor & Huesca & $100 \mathrm{~s}$. & 11-VIII-1475 \\
\hline Miguel Montaner & Aniés & 50 s., 0,5 chzs. trig & 17-III-1478 \\
\hline Domingo Canella & Arbaniés & $30 \mathrm{~s}$. & $12-X-1478$ \\
\hline Antón Montaner & Montmesa & 6 chzs. trigo & 1-II-1479 \\
\hline Juan de Morales & Huesca & 5,5 chzs. trigo & 24-II-1479 \\
\hline
\end{tabular}

60 A. Durán Gudiol, La judería de Huesca (Zaragoza 1984), págs. 170-173; cf. AHPH, prot. 327, f. 280 ss.

${ }^{61}$ En 6-VI-1480, de la comanda de maestre Ezmel Avendet; en otras dos comandas de 1480 y 1486; y en una venta de Salamón Almaxech [3-IV-1486].

${ }_{62}$ Aparece prestando a Juan de Gos, de Latre, 100 s. (20-XI-1455); a Miguel de Sorrosal, de San Julián de Banzo, 2 cahíces de trigo (28-XI-1455). Además, aparece como testigo de seis comandas entre 1455-59. En 1459 se testimonia la posesión de una viña en San Jorge.

${ }^{63}$ Cf. Benedicto Gracia, «Documentos acerca del funcionamiento del sistema de insacul ción», págs. 339-341 
Nombre DeUdor

Juan de Jurdán

Pedro de Cereso

Sancho Campo

García de Banzo

Jaime Ralla

Domingo de Orós

Martín de Belsué

Ferrer Ferrández

Antón Pérez de Pueyo

Beltrán de Carrera

Guillén de Lop

Martín Barrio

Mahoma Ezquerro

Juan de Gabarre

Martín de Mabila

Concejo de Grañén

Pedro Vicient

Manuel Rasal

Domingo Gabarre

Juan de Ansón

Ferrer de la Casa

Pedro Mifrau

Juan de Allué

Pedro Malo

Bartolomeu Petro

Castán Relequín

Juan de Sarasa
LOCALIDAD

Nueno

Huesca

Boltaña

S. Julián de Banzo

Lupiñén

Biescas

Apiés

Tramacastilla

Tramacastilla

Biescas

Sandiniés

Castilsabás

Cuarte

Huesca

Angüés

Grañén

Angüés

Huesca

Anguiés

Huesca

Tramacastilla

Asín

Jarlata

Tramacastilla

Panzano

Sandiniés

Ortilla
IMPORTE DEUDA

$340 \mathrm{~s}$.

3 chz trigo

$360 \mathrm{~s}$.

$120 \mathrm{~s}$.

9 chzs. trigo

$100 \mathrm{~s}$.

$32 \mathrm{~s}$.

$105 \mathrm{~s}$.

$2.100 \mathrm{~s}$.

$220 \mathrm{~s}$.

$228 \mathrm{~s}$.

$500 \mathrm{~s}$.

$200 \mathrm{~s}$.

5,5 cuart. aceite

15 chzs. trigo

100 chzs. trigo

1 cuart. Aceite

12 chzs. trigo

$55 \mathrm{~s}$.

$200 \mathrm{~s}$.

$400 \mathrm{~s}$.

7,5 cuar. aceite

$200 \mathrm{~s}$.

$170 \mathrm{~s}$.

23 chzs, 2 fgs. trig

$340 \mathrm{~s}$.

$51 \mathrm{~s}$.
Fecha

23-IV-1479

22-XII-1479

6-VI-1480

5-X-1480

18-X-1480

14-XI-1480

11-IV-1481

29-IV-1482

2-V-1482

2-V-1482

5-V-1482

26-VII-1482

8-IX-1482

20-IX-1482

30-X-1482

23-XI-1482

14-XI-1482

19-XI-1482

20-XI-1482

9-XII-1482

10-II-1483

21-III-1483

27-III-1483

3-IV-1483

3-IV-1483

9-IV-1483

26-XI-1483

La actividad crediticia adquiría ocasionalmente formas variadas. Así, el 14 de noviembre de 1480 establecía un contrato de «meytadería» con un vecino de Puent de Luna por el que le entregaba tres vacas por un periodo de siete años (Apéndice, doc. $\mathrm{n}^{\mathrm{o}}$ 17). 
Por lo que respecta a JucÉ AlAZAR (21), la primera fecha en que aparece es el 4 de julio de 1475 como testigo en un albarán de los judíos, y la última el 6 de mayo de 1476, como testigo en una comanda de Jucé Xuén. Mosé Alazar (22) sólo figura el 25 de junio de 1481 como testigo en una comanda de Jacob Xuén.

En lo sucesivo, la información que tenemos de los médicos restantes es mucho más escasa. Así, Jucé Almacarén (23), «cylúrgico», es mencionado como testigo en una comanda de Jehudá Cavatierra el 22 de enero de 1445.

Nicín Hanoquá (24) es citado ya el 10 de enero de 1448 como testigo en la cancelación de una comanda. Aún en 1472, «maestre Necín Fanoca, judío, mege, hijo de Jucé de las Infantas», vendía, por nueve cahíces de trigo, una comanda contraída en 1461 por mosén Juan de Urriés ${ }^{64}$. Más tarde, el 3 de marzo de 1480 «Mossé Hanoca, Acach Anoca y Necín Hanoca, mege, judíos de Huesca», vendían a María de la Raga, «un plantero de quasi doze peonadas. Item otro plantero o campo contiguos [...] sito en Sant Cebrián, que afronta con la Sinoga [...] por precio de setezientos sueldos» ${ }^{65}$. La extensión de sus créditos se limita a localidades de la Hoya de Huesca ${ }^{66}$.

Pero Nicín también figura como deudor, entre otras, de una comanda de $40 \mathrm{~s}$. contraída con Violant de Alcalá por unas casas en la judería; y en 1483, con su hermano Acach, zapatero, debiendo 1.160 s. a Violant de Bolea y 2.000 s. a Beltrán de Aosún.

Abram Usiello (26) era examinado en 1453 como cirujano, aunque otra fuente le califica de «mege» ${ }^{67}$. En 1463 había sido clavario de la aljama, pagando 300 s. de una comanda contraída por ésta, en la cual es mencionado como «fisiquo».

Numerosas escrituras parecen hacer referencia a los créditos proporcionados por Abram Usiello. En las comandas suscritas por Juan de Tarazona, detalladas más adelante, Usiello es calificado de «trapero», de lo que se inferiría que pudiera realizar otras actividades. Sus deudores siguen siendo habitantes de localidades pertenecientes a Huesca y a la Hoya.

${ }^{64} \mathrm{AHPH}$, prot. 302, f. ${ }^{\circ}$ (21-II-1472).

${ }^{65}$ AHPH, prot. 317, f. 49.

${ }^{66}$ Entre ellos, uno de 160 s. a Bernart de Ibos, de Lupiñén (14-IX-1470); de 8 fanegas de trigo a Pedro de Arza, de Huesca (14-V-1482); de 1 cahíz y 8 fanegas de trigo a Jaime Regla, de Lupiñén (22-II-1483); de 64 s. a Miguel de Abay, de Huesca (17-XII-1483); de 29 s. a García Calvo, de Bolea (24-II-1486); y de 50 s. a Martín de Bayle, de Liesa (16-VI-1486). En este último Nicín es calificado de «trapero».

${ }^{67}$ ACA, reg. 3370, f. o 8v, cit. ArCo, «La aljama judaica de Huesca», pág. 292. 
Nombre Deudor

Juan de Fuent

Pedro de Arán

Miguel Añón

Martín Giménez

Pedro de Tardienta

Violante Martínez

Pedro Ciprián

Martín de Santa Olaria

Juan de Tarazona

Jaime de Sant Aznar

Armant de Momas

Miguel de Esquo

Antona de Opna

Juan de Tarazona

Domingo de Pano

Juan de Tarazona

Gil de Salabet

Antón de Alquézar

Pedro Font, presbítero

¿?

Juan de Ceresola

Arnalt Ferando

Pedro Barluenga

Antón de Alquézar

Andreu de San Ginés

Pedro Franquo
LOCALIDAD

Huesca

Almudévar

Almudévar

Huesca

¿?

Huesca

Ayerbe

¿?

Huesca

¿?

Huesca

Plasencia

Huesca

Huesca

Luna

Huesca

Lanaja

Huesca

Montearagón

¿?

Huesca

Huesca

Huesca

Huesca

Huesca

Huesca
IMPORTE DEUdA

274 s., 4 drs.

$27 \mathrm{~s}$.

$90 \mathrm{~s}$.

$200 \mathrm{~s}$.

$180 \mathrm{~s}$.

$100 \mathrm{~s}$.

$100 \mathrm{~s}$.

$173 \mathrm{~s}$.

$385 \mathrm{~s}$.

$72 \mathrm{~s}$.

$340 \mathrm{~s}$.

$58 \mathrm{~s}$.

22 s., 6 drs.

276 s.

10 chzs. trigo

$168 \mathrm{~s}$.

$28 \mathrm{~s}$.

$1.060 \mathrm{~s}$.

$126 \mathrm{~s}$.

$70 \mathrm{~s}$.

$1.140 \mathrm{~s}$.

$2.280 \mathrm{~s}$.

$560 \mathrm{~s}$.

$1.560 \mathrm{~S}$.

$1.038 \mathrm{~s}$.

$144 \mathrm{~s}$.
Fecha

27-II-1467

13-VIII-1467

13-IX-1467

13-IX-1467

24-XI-1467

19-XII-1467

17-I-1468

25-II-1468

24-IV-1468

24-VIII-1468

15-XII-1468

15-IV-1469

28-I-1470

17-III-1471

31-III-1471

31-III-1471

21-VII-1471

21-VII-1471

11-IX-1472

14-I-1473

30-IX-1476

9-X-1476

15-X-1476

17-X-1476

4-II-1477

25-II-1477

En 1474 Abram Usiello es elegido dayán de la aljama de Huesca por la mano mediana y menor, y en 1476, adelantado y consellero por la mano mayor, aunque fallece pronto, porque en 1478 es elegido contador por la mano mayor, pero la elección se impugna por haber fallecido ${ }^{68}$.

${ }^{68}$ Cf. Benedicto Gracia, «Documentos acerca del funcionamiento del sistema de insac lación», págs. 335-338. El 13-IV-1477 Astruga Anpinaz aparece mencionada como tutora de Simonico, hijo de Abram Usiello. 
De Mossé Cocumbriel (26) sabemos que es testigo en la cancelación de una comanda de Acach Argellet el 14 de noviembre de 1454, en la cual figura mencionado como «mege». Mossé CoHÉn (27) obtiene el 2 de marzo de 1456 la licencia de medicina ${ }^{69}$. Y rabí Eliezer Alintienz (28), que en 1467 figura como examinado de cirujano ${ }^{70}$, está a punto de bautizarse en $1489^{71}$. ABRAM PAPUR (29) es mencionado el 24 de agosto de 1470 como testigo en una comanda de Semuel Gastón, y por su parte, Jucé TADROZ (30) «mege», lo es el 10 de noviembre de 1474 en otra de Gentó Argellet.

SALAmÓn NATÁn (31) sólo es conocido por las comandas contratadas. Un documento de 2 de febrero de 1475 en el que aparece prestando ocho piezas «blancas» a Juan de Orós, tejedor de Gabín, le califica de «mercader». El ámbito geográfico de sus comandas sigue siendo la Hoya de Huesca, a excepción de una en el Valle de Tena ${ }^{72}$.

JuCÉ D'IXIA (32) y JuCÉ FRAD (33) aparecen mencionados en la lista de casatenientes judíos de Huesca de $1475^{73}$. El nombre de Salamón AnPInaz (34) aparece tachado en la lista de la aljama de los que juran no cobrar usura, realizada el 23 de enero de 1476. AÇACH XuÉn (35), «mege», es citado por primera vez en una cancelación de 1480. En 1487 vuelve a figurar como testigo en una comanda de Acach Cocumbriel, y en abril de 1489, testifica en una carta de su padre, figurando como rabí. El último dato que hace referencia a él en los protocolos es como testigo en una venta de Aym Tortoxí, realizada en 26 de agosto de 1490. Dolz Elnieto (36) también es mencionado dos veces como testigo, el 17 de septiembre de 1480 en una comanda de Mossé Raenas, y en 1482, en una carta de Eliezer Adder.

${ }^{69}$ ACA, Cancillería, reg. 3295, f. ${ }^{\circ} 173$.

70 ArCo, «La aljama judaica de Huesca», pag. 292.

${ }^{71}$ BAER, Historia de los judíos en la España cristiana, págs. 485-488.

${ }^{72}$ En concreto, de 700 s. a Baltasar de Azafra, de Aniés (17-II febrero-1475); de 130 s. a Juan Pastor, de Huesca (4-IV-1475); de 60 s. a Juan Orús, de Gavín (11-IV-1475); de 1.100 s. a Francés de Salillas, de Huesca (5-X-1475); de 560 s. a Juan de Ceresuela, de Barluenga (5-X-1475); y de 540 s. a Francés de Salillas, de Huesca (14-V-1476). Esta última comanda fue cancelada por Abram Ossiellyo, tutor de la hija de Salamón Natán.

${ }^{73}$ Benedicto Gracia, «La aljama de los judíos de Huesca a fines del siglo XV», n $56-57$. 


\section{APÉNDICE DOCUMENTAL}

1

1409, abril 10

Carta de obligación de maestre Bernat del Soler, piquero, que es encargado por Ahym Avinardut de hacer dos sepulturas para los padres de éste.

AHPH, prot. 277, f. $^{\circ} 20$

Maestre Bernart del Soler, piquero Osce. Me obligo a vos, maestre Ahym Avinardut, físico, judío Osce, yo obrar dos sepulturas en el fossal nuevo de los judíos de Huesca, el cual compró Juceff Avinardut, físico judío quondam, padre vuestro, yes a ssaber de XI palmos e medio de cobdos en largo, e quatro palmos e toda mano de amplo cada una, dius tierra de una tira de exellares e sobre aquéllos otra tira de perpenes, si quiere piedras que liguen los exallares e sobre los ditos perpenes una tonba que sía de XI palmos e ditas piedras sean assentadas con calcina bien e proveyto, sabien a un maestro e periglo e que la dita tonba sía sana e sencera, de aquí al primero día del mes de novienbre primero venient por precio [...] de quatrozientos sueldos [...] actum X abril a MCCCCIX. Testes Martín Fortunyo, speciero, e Mussé Tora, sastre, judío Osce.

1411, septiembre 25

Domingo Pérez Bonanat y otro mercader se obligan a pagar 1.300 s., a la vez que alquilan, con ciertas condiciones, una casa a Haym Avinardut, situada en la ciudad fuera del barrio judio, en el barrio de Campaneros.

AHPH, prot. 18, f. $^{\circ} 51 \mathrm{v}$

Yo, Domingo Pérez Bonanat, e yo, Aznar de Bolea, mercaderos Osce [...] prometemos e nos obligamos dar e pagar a vos, maestre Haym Avinardut, físigo, judío Osce, mill e trezientos sueldos dineros jaqueses d'aquí al día e fiesta de Todos Santos del anyo primero venient, que vos nos havedes emprestados de puro cabal e si dentro el dito plazo no vos daremos los ditos $\mathrm{MCCC}^{\mathrm{os}}$ sueldos queremos de que d'ally adelant vayan a ganancia [...] specialmente yo, dito Domingo Pérez, obligo a vos unas casas mías francas, ditas stadas Osce, al barrio de los Campaneros que afrontan con casas de Lop Sánchez Dovernes e con casa de Martín Pérez de Ladux e con carera pública [...].

Actum Osce XXV días de setiembris anno MCCCCXI. Testes: don Jayme d'Aínssa e don Sancho Burro, clérigos beneficiados en la Seu de Huesca e Jacob Avinardut.

Yo, Domingo Pérez Bonanat, Osce, atorgo e do a loguero a vos, maestre Haym Avinardut, físico Osce, unas casas mías sitiadas al barrio de los Campaneros que afrontan [sic], por 
tiempo de hun anyo contadero del último día del mes de octubre primero venient adelant, por precio de cient e cinquenta sueldos jaqueses, los quales atorgo haver recebido de vos en mi poder, e si por ventura hy avrá menester, adobo que aquello prometo yo fazer a mis messiones, empero que vos non las podades logar, lexar, prestar a persona alguna sino a vuestros fillyo e gerno e que en fín del dito tiempo me restituyades e livredes las ditas casas sienes impediment alguno. Et yo dito maestre Haym recibo las ditas casas a loguero. Actum Osce. Testes ut supra.

Die qui supra Osce. El dito Domingo Pérez promiso e atorgó que si el dito maestre Haym querrá tener las ditas casas e las havrá a tener por tiempo de hun anyo aprés si quiere que lo pueda fazer, sirviéndose el dito Domingo Pérez sienes usura de los MCCC sueldos sobreditos juxta la carta de loguero exposéndolo a saber maestre Haym tres meses antes que las querrá e maestre Haym quiso que él serviéndose de las casas e no ganasen res los ditos MCCC sueldos durant el dito anyo. Testes qui supra.

1415 , septiembre 3

Alazar Çadot, judio de Calatayud, hace testamento a favor de su hermano Juan Sánchez de Calatayud (ol. Çalema Çadot) y de Jamila, hija del médico Alazar Avinardut, ya fallecido.

AHPH, prot. 19, f. ${ }^{\circ} 37$

Kalendas septembris, die dominica, anno a nativitati Domini $\mathrm{M}^{\circ} \mathrm{CCCC}^{\circ} \mathrm{XV}^{\circ}$. En nonbre de Dios. Alazar Çadot, fillyo de Açach Çadot, judío de Calatayu, quondam, jaciendo enfermo, facio e ordeno mi último testamento, por tenor del qual lexo a Jamila, fillya de maestre Alazar Avinardut, quondam, e a Johán Sánchez de Calatayu, olim clamado Calema Çadot, hermano mio, habitante en Monçón, todos mis bienes mobles e sedientes e todos mis nombres e acciones, assí que aquellos partan entre sí por yguales partes, e a los quales madre e hermano mio lexo, pago instituo e ordeno herederos mios universales en tal manera e con aquesta carga que ellyos satisfagan, paguen e contenten a Bonina, mercader judío de Monçón, padrastro mio, todo e qualquiere que por mí ha espendido el dito Bonina en ferme mostrar letras e scrivir e en comer, bever, vestir, calçar e en manera otra alguna de las quales expensas sia creydo el dito Bonina por jurament suyo, el qual faga según ritu de judios, et en encara quiero que satisfagan a Jacob Avinardut, judío Osce, quienquiera que ha espendido por mi e por mi enfermedat e espenderá d'aquí adelant e encara satisfaga las [ilegible] mis injurias que por verdat serán trobadas.

Actum Osce III dias de setienbre, anno MCCCCXV ${ }^{\circ}$. Testes: Sentó Tuba e Sentó Almuzar, judío Osce.

Item, lexo a Alazar Avinardut, fillyo de rabí Jacob Avinardut, judío Osce [ilegible] e por algunos servicios que me ha feyto quaranta florines. 
1428, junio 29

Jucé Avinardut se presenta ante los jurados de la ciudad para exigir se cumpla la prohibición de que nadie transite por la judería con armas, según establecen los Estatutos de la ciudad.

AHPH, prot. $178, f^{\circ} 177 v-178 r$

Eadem die. Maestre Jucé Avinardut, judío, fue personalment constituydo devant don Pero d'Aspa, jurado de la ciudat de Huesca, e Sancho Scudero, jurado, e por justicia. E present mí, notario, e los testimonios dius scriptos, el qual maestre Jucé dixo que como stablecido e ordenado fues por la ciudat de Huesca que ningún gent d'armas no entras'en la ciudat sobredita e él veyés huellyo a huellyo que por fuerça aquellya gent entras'en la judería, ellyos fuessen regalías del senyor Rey que los requerían que dassen favor e adextolen aquéllos de la dita judería. Aliter protestó contra los ditos jurados requiriendo a mi, notario, que ende fes carta pública la qual dixo que daría más largament ordenada a mí, notario infrascripto. Testes: Johan de Huerto, habitant en Quart e Jucé Alaquén, judío.

1428 , noviembre 2

El lugarteniente de merino de Huesca, Pero Pardo, pide a varios ciudadanos información sobre la muerte de Bernart de Aspa; entre los peritos figuran Bartholomeu de Civader, cirujano, y Jehudá Cavatierra.

AHPH, prot. $178, f^{\circ} 277 r-v$

Eadem die, el dito lugarteniente de merino clamó por testimonio en la causa present a Jeudá Cavatierra, judío e cilúrgico, habitante Osce, el qual juró a Dios e a la Ley de Moysés. Interrogado por la jura que havía y si havía conoscido, respondió e dixo que sí. Interrogado si sabía que havíes stado ferido en la cabeza, respondió e dixo que sí, que ferido havía stado. Interrogado cómo lo sabía. Interrogado si sabía que fues muerto, respondió y dixo que sí que muerto era. Interrogado cómo lo sabía, respondió e dixo porque lo havía visto morir e aprés, muerto. Interrogado sobre las otras cosas, respondió e dixo que no hí sabía res.

6

1434, mayo 10

El merino de Huesca se desplaza al monasterio de Santa M. ${ }^{a}$ de Monflorite para comprobar que la mula de Jucé Avinardut lo había matado.

AHPH, prot. $181, f^{\circ} 73 r-v$

Publicum instrumentum. Die X madii. En el monasterio de Santa María de Montflorit, el muyt honorable e circunspecto varón monssén Johan Lóppez de Gurrea, regient el oficio de la goberna- 
ción en el regno de Aragón e merino Osce, dixo qui como él haviés mandado a Pero Pardo, scudero, lugarteniente suyo de merino Osce, executar la mula que era stada de maestre Jucé Havinardut, quondam, judío, por razón qui se dezía la dita mula haver muerto al dito maestre Jucé, por levar la calonia del omicidio e segund Fuero, tal execución de calonia del dito omicidio no se pudiese fazer ni levar; por tanto el dito mossén Johan, merino Osce, atorga haver recebido en su poder la dita mula e havida en su poder ha tornado e mandado tornar e livrar aquélla a los herederos del dito maestre Jucé por do requiere a mí, notario infrascripto, que ende fes carta pública. Teste: Domingo Infant, notario en Calatayut habitante, e Grabie d'Arribas, habitant en Monçón.

1436, septiembre 3

Johan de Amellyas, mercader, exculpa a Açach Cavatierra de ciertos robos, que por error le había atribuído.

AHPH, prot. $183, f^{\circ} 125 v-126 r$

Ordinación de deffinición [...] Johan de Amellyas, mercadero, ciudadano de Huesca, atendient e considerant que en los tiempos pasados agora en mi casa yo haya trobado en mis mercaderías e bienes en grant quantidat de grandes furtos e robos e por informaciones de algunas personas yo haver indicios e supposecciones, vos, Acach Cavatierra haver seydo consient e participant en los ditos furtos de las ditas mis mercaderías presas contra mi voluntat [...] yo stava indignado contra vos, Acach, a demandar aquellyos bienes [...] et aprés, yo haya havido verdadera información vos seyer inmune e sine culpa de las cosas sobre ditas [...] atorgo e verdaderament reconosco vos no seyer culpable en trato feyto ni consentimiento de los ditos furtos e robos [...] en unas mercaderías e bienes [...] sienes sin culpa alguna [...] Et con aquesto absuelvo, quito, relaxo e difinesco a vos dito Acach.

8

1440, agosto 16

Anthón de Sangüesa, habitante de Huesca, tiene en comanda de Sentó Cavatierra, maestro en medicina, ocho florines importe por la curación de una úlcera que padecía.

AHPH, prot. $81, f^{\circ} 176 r$

Comanda de Sentó Cavatierra. Die XVI Augusti e anno quo supra, Osce. Yo, Anthón de Sangüesa, civis Osce, confieso tener en comanda depósito mío de vos, Sentó Çavatierra, maestro en medicina, judío Osce, son a saber hueyto florines de oro. Renunciant a toda excepción de frau, de enganyo, et prometo e me obligo render et si danyos costas. Renuncio mi judge et al privilegio de la ciudat de Huesca. Renuncio firmas de dreyto, fiat large. Testes, Martín de Granyen e Açach Hanoca, judío Osce. 
Eadem die, Osce. Yo, Sentó Çavatierra, judío Osce, me obligo curar e dar vos curado a vos, Anthón de Sangüesa, civis Osce, de huna vúlcera que vos tenedes en la pierna dreyta. Et por tanto me obligo dar vos sano e curado de la dita vúlcera. Fiat large. Ut decet empero yes assí que vos dito Anthón siades tenido tener el regimiento que yo vos daré en el regimiento de vuestra pierna, large. Testes qui supra.

9

1441, agosto 16

Violant de Santa Fe, viuda de Jaime de Santa Fe , da testimonio de haber recibido de Ramón Oncina (ol. Açach Cavatierra) y de Astruga Havinbitas el importe de una deuda de 500 s. que habían contraído el l6 de marzo de 1434.

AHPH, prot. $186, f^{\circ} 123 v-124 r$

Albarán. Die XVI Augusti 1441, Osce. Yo, Violant de Santa Fe, muller de don maestre Jaime de Santa Fe, ciudadano quondam de la ciudat de Huesca, atorgo haver havido en poder mío recibido de vos maestre Ramón Onzina, cirúrgico, ciudadano de la dita ciudat, olim clamado Açach Cavatierra, de Astruga Havinbitas, Duenya Havinbitas, muller vuestra, quondam, e de Jehudá Cavatierra, judío, habitantes en la ciudat sobredita, son a ssaber cincientos sueldos dineros jaqueses, los quales vos sobreditos, todos ensemble e cada uno de vos por sí e por todo erades tenidos e obligados de dar, render con carta de comanda que feyta fue en la ciudat de Huesca a XVI días del mes de março, anno a Nativitate Domini $\mathrm{M}^{\circ} \mathrm{CCCCXXXIIII^{ \circ }}$, recibida e testificada por el notario infrascripto [...] absuelvo a todos vosotros [...] consiento que la dita carta sía tallada [...] no puede seyer más sacada en pública forma [...] Testes: Jayme Gómez de Alcalá, scudero Osce e Martín de Seral, vecino de Huesca.

1442, junio 28

Albarán de la aljama de los judíos de Huesca a favor de Acach Arrondí, por importe de 140 florines, como consecuencia de una sentencia arbitral dada por Mosé Argelet.

AHPH, prot. 202, f. ${ }^{o} 192 v-193 r$

Albarán de la aljama de los jodíos Osce. Yo, maestre Isach Arondí maestro en medezina, judío, atorgo haver havido e recebido de la aljama de los judíos de la dita ciudat e singulares de aquélla, son a saber aquellos cient e quaranta florines de oro e peso de Aragón, los quales la dita aljama e singulares de aquélla yeran tenidos dar a mí por vigor de una sentencia arbitral, dada por don Mosé Argellet, judío Osce, dada fue en la ciudad de Huesca veneris a seys días del mes clamado de marhesvan, anyo de cient novanta e hueyto a conto de judíos, testificada por rabí Salamón, judío Osce. Et porque de los ditos CXXXX florines me atorgo seyer pagado dentro del tiempo del 
dito compromís, por manos de Mosé Cogumbriel, adelantado de la dita aljama en el anyo present e de otros clavarios, me atorgo seyer pagado de todas e qualesquiere otras quantías de dineros [...] me fuesen tenidos dar [...] Testes, don Johan Ponz, clérigo Osce, et Abadías Benluengo, judío Cesarauguste e Isach Abenhayón, judío de la ciudat de Toledo [...].

\section{1}

\section{7 , enero 17}

Bellyta Moriel y su hijo Sentó Ambrón reclaman a Ysach Rondí por haber abierto una puerta y una ventana en la propiedad de estos.

AHPH, prot. $86, f^{\circ} 19 r-v$

Carta pública de Sentó Ambrón.

Eodem die Osce. Devant las puertas de unas casas e corral, sitiadas en la judería de la ciudat de Huesca, cerca la Sinoga mayor que confronta con casas de Sentó Sanoga e con el banyo e con casas de Sentó Ardit e con casas de maestre Ysach Rondí, mege, e con calliço que no ha sallyda, presentes mí, notario, e los testimonios infrascriptos, comparecieron fueron personalment constituydos Bellyta Moriel, muller de Vidal Ambrón, quondam, e Sentó Ambrón, fillyo suyo, judío, habitant en la dita ciudat, los quales diseron e proposaron tales o semblantes paraulas, que como las ditas casas e corral fuesen suyas e de Sol Moriel e posedisen aquéllas por suyas, pacíficament et como yo, notario, et los testimonios veyésemos aquellyo era una paret que estaba entre las ditas casas e corral et las casas del dito maestre Ysach, que havían de fiesto fabricado e ubierto una puerta e dos finestretas las quales dizieron los ditos Bellyta e Sentó que havían obrido e feyto abrir e fabricar el dito maestre Ysach et como aquéllo se fuese feyto en gran prejudicio e danyo suyo, dijeron que protestaban del crebantamiento de su posesión e de qualesquiere danyos, costas e mesiones, e por la dita razón les conveniese fazer e sustener mayorment como las ditas casas e corral fuesen aprensas a manos de la Cort de los dayanes de la dita aljama et protestaron que todo lo sobredito podiesen demandar e afrontar en su tiempo e lugar et devant qualesquiere juzge o juzges que a ellos será bien visto, requiriendo a mí, notario subescripto, que de lo sobredito les fases carta pública, la qual darían más largament ordenada. Testes: Miguel Cit, menor de días, Symuel lo Nieto e Haym Axeuilí, judíos Osce.

1466, febrero 3

Abram Bivach hace de intermediario entre el médico Ximeno Panzano de Huesca y el médico Miguel de Jaca para la entrega del Canon de Avicena.

AHPH, prot. $74, f^{\circ} 6 r$

Die III febroarii 1466. Maestre Ximeno Pancano, mege Osce. Atorga haber recebido de maestre Miguel de Jacca, por manos de maestre Abram Vivag, un libro clamado el Canon de 
Avicenna e porque se tiene por contento refren en. Testes, Johan Pardo e Jucé Allaquén, jodío Osce.

Eadem die. El dito maestre Ximeno definió al dito maestre Abram de qualquiere cosa que fasta la present jornada le fuese tenido en qualquiere manera e porque se tiene por contento atorgo el present albarán. Testes, qui supra.

\section{3}

1470, abril 14

Maestre Habram Bivach se presenta en casa de Johan de Cuenqua a reclamar el «pastel» que le había encargado.

AHPH, prot. $308, f^{\circ} 52$

Carta pública de maestre Habram Ambivaj [...] 17 de abril en Huesca, dentro de las casas que eran de Bavari, que agora son de Guallyarda e de su marido, Johan de Cuenqua, delant de la dita Guallyarda compareció maestre Ambivaj e demandó que do era Johan de Cuenqua, marido suyo, e ella dixo que no y era et el dito maestre Habram dito que como [espacio en blanco] e no haviese traydo el pastel ni lo aviesse levado dentro el mes de março último pasado, segunt era obligado e tenido, que protestava e protestó del danyos e pérdidas [espacio en blanco] e requirió por mí seyer ffeyta carta pública... Testes: Vlasco de Jarne, ferrero, et Ezmel Vendent, judío Osce.

14

1475, junio 11

Información según la cual Jaco Xuén, estando enfermo, y su mujer, ausente en una boda en Zaragoza, habían confiado la custodia de su casa al maestre Vidal Cap. Este les habría robado joyas y varios enseres, escapándose después para refugiarse en el castillo de Montearagón.

AHPH, prot. 153, f. ${ }^{o} 73 v-74 r$

Información. Die XI junii, Osce. don Martín de Arag, lugarteniente de justicia, president D. Ramón d'Sangüesa, prior, prendieron la información infrascripta por virtut de los statutos.

Primo Jaco Xuén, judío Osce, sticado por Asensio Sant Martín, nuncio, qui juró, responde que, días pasados el deposant seyendo enfermo en casa de su ermano Simuel e la muller del deposant a bodas a Çaragoça, visto que su casa stava sola, fiando Vidal Cap, judío ermano de Perfet Cap, rogó al dito Vidal que yse a dormir a la dita su casa, con hun moço del ermano del deposant, clamado Çaçón, jodío de Biel, e contestó que el dito Vidal robó la casa del dito Jaco e falagó al dito Çaçón, que consentiese en ello e le dió por consentir XV e dizasiet florines falsos, del qual robó dos o tres collares de perlas e hun spiello e peyne d'argent e sciertas tovallas, una camisa de almerina e cortinas con barras negras de lienço bizcayno e otras muytas cosas. Interrogado cómo lo sabe, responde e dize que porque faltado de todas estas cosas se querellava el deposant e fue 
ad Ayerbe do estava el dito Çaçón e le dixo todo lo sobredito e le mostró los florines falsos qu'el dito Vidal le avía dado por consentir en el dito furto e con esta muestra e testimonio el deposant e sus parientes persiguieron al dito Vidal por justicia e el dito Vidal e su ermano Perfet fuyeon a Montaragón e allí instant el desposant fueron presos en Montaragón e de aquí sallió tracto que le tornasen el furto e que fuesen sueltos e lo tornó el padre de los ditos Vidal e Perfet las perlas e algunas otras cosas por medio de Azerían Xuén e fueron sueltos; es verdad que no lo cobró todo por no saber a principio con verdad que le fallía; es verdad que antes fue preso el Vidal en la Cort del bayle e allí empeçó de atorgar el furto de la qual prisión de la casa de bayle fue dado a capliençia e después se fuyó el dito Vidal al castillo de Montaragón e después fueron emparados e detenidos los ditos Vidal e Perfet en Montaragón, que stavan allí foydos seqretament, e después con el tracto suso dito e fueron sueltos e más que ha oído decir que han feyto una carta falsa a los fillos de maestre Vidal.

1475, diciembre 8

Carta pública certificando el fallecimiento de maestre Sentó Cavatierra.

AHPH, prot. $312, f^{\circ} 275 v$

Carta pública de la muert de maestre Sentó Cavatiera.

Sía manifiesto a todos que a gueyto días del mes de deziembre, Osce, en la judería dentro hun palacio de hunas casas sitas en la dita judería de la que confrontan con casas de Accaz Cabanyas e carera pública, compareció e fue personalment constituído yo, Blasco Colduras, e los testimonios dius scriptos, en el qual palacio en derredor de hun scanyo stavan muytas duenias judías plorantes e judíos, e dizían que ploragevan que era muerto maestre Sentó Cavatierra et en continent descorellyavan la cara del tal por muerto e yo noté e los testimonios dius scriptos veyamos aquéllyo seyer el cuerpo de maestre Sentó Cavatierra, mege [espacio en blanco] Cavatierra fillyo del dito Sentó requirió seyer ne feyta carta pública. Actum Osce a gueyto días del mes de deziembre anno MCCCC setanta cinquo. Teste: Pedro de Ena barbero et Accac Alguer, judío, habitantes en Huesca.

1480, octubre 17

Maestre Jeudá Cavatierra da poder a Abraham Almosnino para la reventa de unas casas suyas junto a la sinagoga.

AHPH, prot. $300, f^{\circ} 94 r$

Carta pública de Abram Almosnino, judío Osce [...] fue dada poder e facultat por maestre Jeudá Cavatierra, metge judío habitante Huesca, a Abram Almosnino [...] que pudiese demandar 
et obtener del magnífico Martín Gil de Palomar, senyor de Argavieso, que le faga revendición de dos cartas de hunas casas sitas en la judería de la ciudat que confrontan con casas de Jehudá Cavatierra con la entrada de la Sinoga et casas de Acach Cabanyas et de Mosé Cabanyas et casas de Hayn Alxech e carrera pública, las quales casas de suso confrontadas, el dito maestre Jehudá dixo havía vendido Martín Gil de Palomar en fe y por cubierta [...] et esto fue quando havía vendido las ditas dos tercias de quasas al dito Abram Almosnino. Testes: Martín López de Cerisuela et Abram Alitience, judío Huesca.

\section{7}

1480, noviembre 14

Ezmel Avendet entrega a Miguel de Buen, de Puent de Luna, tres vacas para que las críe y tener a medias los beneficios.

AHPH, prot. $376, f^{\circ} 258 \mathrm{v}$

Carta de meytadería de maestre Ezmel Abendent.

Eadem die. Osce. Yo Ezmel Abendent judío Osce, do a medias a vos Miguel de Buen, habitante en el lugar de Puent de Luna, tres vacas de pelo vermello a tiempo siete anyos contaderos de oy adelant, las quales ayades vos dito Miguel de Buen a medias e [ilegible] aquéllas con las condiciones siguientes: primo que seades tenido tener e custodiar e guardar aquéllas e d'aquéllas surtirán durante el dito tiempo estando el dito tiempo aquéllas a lo que d'ellas surtirá que partiremos a medias.

Item, que seades tenido de darles lo necesario a vuestras espensas. Item, que si alguna vaca o buey que d'ellas surtirán o se muera o mataran lobos o por otra razón que siamos tenidos partir el cuero e carnes a medias. Item, todo lo que surteyrá así quesos como mansejos seamos tenidos partir a medias. Item, en fin del tiempo que seamos tenidos, partir lo que y abía a medias. E con aquesto yo dito Miguel de Buen prometo e me obligo dar vos bueno verdadero [...] Testes: Pero Gavín, de Biescas, e Semuel Argelet, judío Osce.

1481, julio 12

Varias judías venden a Violant de Alcolea sus casas, corral y huerto contiguos en el barrio de Amillyas.

AHPH, prot. $318, f^{\circ} 120 \mathrm{v}$

Vendición facién de dona Violant de Alcolea, viuda, Osce. Strellya Benardut, alias Cohén, judía, vidua, muller que fuese de maestre Astruz Cohén, quondam, e Mossé Cohén, judío, apotecario, e Bonadona Alantienz, judía, muller del dito Mossé Cohén [...] de Huesca, [...] vendemos [...] a Violant de Alcolea [...] respetivament, nuestras casas, coral e güerto contiguos. [...] en la 
judería [...] barrio clamado Amillyas, confronta con casas de Azerián Xuén, con casas de Josuas Parexo e carera pública [...] por mil cincientos sueldos [...] haver avidos [...]. Testes Johan Serra, studiant en dreyto, Mossé Alazar, judio, menor, nieto de Simuel lo Nieto.

1488, febrero 29

El pastor Guyllem de Cassabona está enfermo de una parálisis del lado derecho y acude al médico Acach Arondí para que lo cure.

AHPH, prot. $11045, f^{\circ} 6$

Obligación de Guyllem de Casabona, pastor.

Die XXVIIII Febroari anno M $^{\circ}$ CCCCLXXXVIII, Osce. Yo, Guyllem de Cassabona, pastor de Martín de Quincano, del lugar de Lopinyén, atendido y considerado esté detenido de una enfermedat o dolencia e esté casy baldado y no me pueda baler bien del braço drecho y de la pierna e, vos, mestre Acach Arrondí, judío, mege, de Huesca, ofrescays en poder del present notario guarirme de la dicha enfermedat a conoscimiento de maestre Sera, mege, Osce, fasta por todo el mes de marco primero venient me obligo de vos dar para las medecinas [entrelíneas tachado: es a saber XXV sueldos e depués que sera conoscido] y por vuestros trebaxos xixsanta y quatro sueldos dineros jaqueses, dita obligación. Juro a Dios. Et yo, dito maestre Acach Arrondí, meche, juro que si dentro el dito tiempo no será guarescido bien a conoscimiento del dicho maestre Sera, meche, de no demandar la dita quantidat, dius pena de perjurio, large. Videcet cum obligacionibus.

Item más es pacto que sy antes de ser complido el dito tiempo el dicho Guillem se yrá y no querrá que sea curado por el dito meche, que sea tenido de paguar lo que está abenido por ellos de suso, e mas dió por principal y fianca a lo sobredito a Gil Pintado, present. El qual le plugo e quisso ser obligado según el dito Guillem et juró.

Testes: Mosén Juan de Aranda, presbítero et Acach Alguer, judío Osce.

1490, julio 21

Los jurados de Huesca conceden a Açach Arrondí licencia para tomar agua de la acequia mayor para su huerto.

AHPH, prot. $364, f^{\circ} 77 v$

Licencia. Nos, Pedro Franco e Johan de la Badía, jurados Osce, atendientes vos, Acach Rondí, judío, mege Osce, teneis hun güerto junto a nuestras casas, sito en la judería Osce, al barrio de Salceras et en aquél no tengays regano ni lo podáys haver, segunt nos han dicho, sino de la acequia mayor que pasa por la dita carrera, por tanto damos licencia a vos, dito maestre Acacg Rondí, 
podays abrir regano de la dita cequia para el dito güerto con que aquél sea fecho de piedra e cubierto de losa e lo hayais a mantener a vuestras propias expensas e con esto vos otorgamos dicha licencia [...] yo, dito Acach Rondí, qui present acepto la dita licencia e prometo e me obligo fazer el regario e canyo a mis expensas e tenerlo cubierto de losas todo tiempo, dius obligación [...] fiat large. Testes: Pedro Labadía e Jucé Anbrón, judío Osce.

Recibido: 01/06/2006

Aceptado: 05/07/2007 
